Research Article

\title{
The Magnitude of Wasting and Associated Factors among Children Aged 2-5 Years in Southern Ethiopia: A Cross- Sectional Study
}

\author{
Selamawit Dires and Moges Mareg \\ Department of Reproductive Health, School of Public Health, College of Medical and Health Sciences, Dilla University, Dilla, Ethiopia \\ Correspondence should be addressed to Moges Mareg; metanmann@gmail.com
}

Received 20 December 2020; Revised 25 February 2021; Accepted 30 April 2021; Published 7 May 2021

Academic Editor: Anil K Verma

Copyright (c) 2021 Selamawit Dires and Moges Mareg. This is an open access article distributed under the Creative Commons Attribution License, which permits unrestricted use, distribution, and reproduction in any medium, provided the original work is properly cited.

\begin{abstract}
Background. Malnutrition accounts for almost half of the global under-five child mortality. Worm infections are one of the immediate and commonest causes that affect the nutritional status of children. There is limited data related to the magnitude of wasting and associated factors among children. Therefore, this study was aimed at assessing the magnitude of wasting and associated factors among children aged 2 to 5 years in the Wonago district of Gedeo Zone, southern Ethiopia. Methods. Community-based cross-sectional study design was conducted. A total of 3324 children aged 2-5 years were included in the study. A pretested semistructured questionnaire was used for data collection, and anthropometric measurements were computed using the World Health Organization Anthro-nutritional software. The multivariate logistic regression analyses with adjusted odds ratio, 95\% confidence interval, and $P$ value less than 0.05 were used to identify the factors significantly associated with wasting. Results. A total of 3273 children aged 2-5 years participated with a $98.5 \%$ response rate. The magnitude of wasting was $13 \%$. The factors like government-employed fathers [AOR $=1.93 ; 95 \%$ CI $(1.08,3.46)]$, child's age range between 48 and 59 months $[\mathrm{AOR}=1.46 ; 95 \% \mathrm{CI}(1.01,2.09)]$, being a male child $[\mathrm{AOR}=1.42 ; 95 \% \mathrm{CI}(1.07,1.88)]$, having diarrheal disease in the past two weeks $[\mathrm{AOR}=0.39 ; 95 \% \mathrm{CI}(0.17,0.90)]$, and bathing less than two times per week $[\mathrm{AOR}=1.42 ; 95 \% \mathrm{CI}(1.03,1.96)]$ were factors significantly associated with wasting. Conclusion. Undernutrition in children is still a problem, and the proportion of wasting was $13 \%$. Government-employed fathers, child's age range between 48 and 59 months, being a male child, having diarrheal disease in the past two weeks, and bathing below two times per week were significantly associated with children's nutritional status warranting close attention by policymakers and stakeholders. For researchers, a further longitudinal study is recommended to get strong evidence.
\end{abstract}

\section{Background}

Nutritional status is the state of the body in a way that is influenced by the food that a person consumes [1]. The nutritional status of children is one of the most important indicators of a household's living standard and determinant of child survival, and it is a strong reflection of countries' development $[2,3]$.

The nutritional status of individuals and population groups is assessed by anthropometric measures (anthropometry is the measurement of the human body). Well-known anthropometric measurements are weight, height, and midupper arm circumference (MUAC) [4]. Certain measurements are expressed as indices, which include weight for age (WFA), height for age (HFA), weight for height (WFH), MUAC for age, and body mass index (BMI) for age. Each index is documented as a $z$-score that describes how far and in what direction an individual's anthropometric measurement diverges from the median [4].

There are several and varied causes of malnutrition which are interrelated with each other and classified as the front line. Most of these related factors are inadequate food intake 
and disease which are determined by several essential factors like household food security, maternal/child-caring practices, political factors, cultural conditions, access to health services, and access to a healthy environment $[5,6]$.

The magnitudes of wasting were high in the age range of 12 and 24 months when dietary inadequacy and diarrheal illnesses are most common [7]. It is connected with poor health in infants and young children. The consequence or complications of wasting are well-known. These are increased risk of illness from infectious diseases [8-10] and death [11, 12].

Research is needed on the risk factors of wasting at different ages and in different environmental and sociocultural settings. This is because wasting represents an acute form of undernutrition, and children who suffer from it face an increased risk of death, increased risk of diseases, and reduced productivity [13].

Globally, almost half (45\%) of all deaths in under-five children were because of undernutrition. This problem puts children more to be prone to severe diseases and responsible for the unnecessary loss of three million young lives annually $[14,15]$. A figure in 2014 showed that there were 50 million (8\%) wasted children globally and from them, 16 million (2\%) were severely wasted. On the other hand, about 151 million under-five children in 2017 suffer from chronic malnutrition and 67 million were wasted $[16,17]$.

In Africa in 2010, about 39.4\%, 24.9\%, and $10.3 \%$ of under-five children were stunted, underweight, and wasted, respectively [18]. In 2015, undernutrition in sub-Saharan Africa accounts for one-third of the global estimate [19]. The rate of malnutrition among children less than five years in Ethiopia is the highest from sub-Saharan and East African countries having $9 \%$ and $8.7 \%$ of wasted under-five aged children. It is also one of the most important causes of disease and mortality among under five children in the country [20, 21].

The trend from 2000 to 2014 in Ethiopia showed that there is a decrease in the prevalence of stunting by $31 \%$ and underweight by $39 \%$. However, wasting declines only by a small proportion. Despite the results observed and ongoing attempts which have been done towards ensuring and minimizing under-five malnutrition, the nation is still facing a very high burden of undernutrition. According to 2014 Ethiopian minidemographic health survey (EMDHS) data, the national wasted children were $9 \%$ and severely wasted were 3\% [22].

This national report also showed that the magnitudes of nutritional problems had regional variations, some with a higher/lower level than the national average including Southern Nations, Nationalities, and People's Region (SNNPR). Wasted children in this region, where the study area is found, were $7 \%$, and severely wasted were $2 \%$ [22]. Moreover, there is a limited study on the magnitude and associated factors of wasting by age classification among under-five children in developing counties, especially in the study area. Therefore, the aim of this study was assessing the magnitude and factors associated with wasting in Wonago district, Gedeo Zone, southern Ethiopia.

\section{Methods}

2.1. Study Aim, Design, and Setting. A community-based cross-sectional study design was employed to assess the mag- nitude of wasting and associated factors among children aged 2-5 years with their mothers who were living in Wonago district. The district is found in the Gedeo Zone, Southern Nation Nationalities, and Peoples Region (SNNPR), Ethiopia. It is located $375 \mathrm{~km}$ southwest of Addis Ababa, the capital city of Ethiopia, $105 \mathrm{~km}$ south of Hawassa, and $12 \mathrm{~km}$ from Dilla, which is the provincial city of Gedeo Zone.

The district is one of the densely populated districts in Ethiopia. The 2015/2016 population data obtained from the district health office showed that the total population reached 145,635 and 29,720 households. Of the total population, $10.43 \%$ are children aged between 2 and 5 years old. There are 18 kebeles (the smallest administrative units of the Ethiopian governance system) in Wonago, one urban and 17 rural kebeles. There are six health centers, 20 health posts, two private clinics, three pharmacies, 33 elementary and junior schools, three high schools, and a preparatory school in the study area.

2.2. Sample Size and Sampling Procedure. Sample size: the study participants included a cohort of children aged 2-5 years of age who were living in the three selected clusters Hasse Haro $(n=983)$, Mokonissa $(n=1310)$, and Wonago kebeles $(n=1031)$.

$$
N=983+1310+1031=3324 \text {. }
$$

Sampling procedure: first, based on residential areas, the 18 kebeles in the woreda were taken as clusters, and from those, three kebeles were selected by lottery method, urban, and rural mix. The study participants were all children aged 2-5 years from these three clusters.

2.3. Data Collection Instruments and Procedure. Two types of instruments (questionnaire and anthropometric measure) were used to collect the required data. A pretested and validated semistructured interviewer-administered questionnaire was prepared in English and translated into Amharic and Gede-uffa and was used to obtain information on factors influencing the nutritional status of children. Besides, the anthropometric measure was used to estimate the nutritional status of the children.

Data were collected by those who can take anthropometric measures of a child and who spoke the local language (Gede-uffa). Data collectors were trained to measure height to the nearest $0.1 \mathrm{~cm}$ and weight with the subjects without shoes and in light clothes to the nearest $0.1 \mathrm{~kg}$, using electronic weighing scales which were calibrated daily. To reduce measurement errors, the child's shoes, braids, and hair clips were removed before measurement. A stadiometer and digital weighing machine were used for height and weight measurement, respectively. In the process of anthropometric measurements, the child was in a stand-up position with feet together and flat on the ground, heels tetchy the back plate of the stadiometer, legs straight, buttocks against the backboard, scapula against the backboard, and arms loosely at their side.

2.4. Data Analysis. The collected data was entered in to computer using EpiData software, and analysis was done using 
Statistical Packages for Social Sciences (SPSS) version 20 software. The data was cleaned, and data integrity was checked. The standard score of WFH and proportions of wasting were estimated. The mother's BMI was determined and used as a factor that may affect the nutritional status of their children. A bivariable logistic regression was used to estimate the relationship of independent determinants of wasting. A multivariable logistic regression model was fitted to identify factors that are associated with wasting by adjusting for the possible confounders. Statistical precision was estimated with a 95\% confidence interval, and statistical significance was declared at a $\mathrm{P}$ value $\leq 0.05$.

The quality of data was ensured by using a digital weight scale, and by calibrating it daily, training of data collectors according to the standard of the WHO measurement techniques, close supervision, and prompt feedback were provided. The data were checked in the field to ensure that all the information was properly collected and recorded. Moreover, a sort of brief daily activity evaluation method was established to correct problems that could be faced during data collection. The consistency of data was maintained through the translation of the questionnaire into two local languages (Amharic and Gedeuffa) and back to English. Before and during data processing, the information was checked twice by two independent people for completeness.

2.5. Operational Definition. Weight-for-height $z-$ score $<-2$ indicates wasting or thinness of children which reflects an acute weight loss, often associated with current starvation and/or severe disease, and it can also be the result of a chronic condition [22].

Undernutrition is a result of food scarcity and/or repeated infectious diseases. It includes stunting, wasting, and underweight [22].

Over nutrition is because of excessive food intake or excessive fat accumulation that presents a risk to health. It includes both overweight (weight-for-height $z$-score $>+2$ and $\leq+3 z$-score) and obesity (weight-for-height $z$-score $>+3 z$-score) [22].

Well-nourished children are those whose $z$-score lies between $>-2$ and $\leq+2$ [22].

Sometimes sick refers to the sickness of mother on the pregnancy of the index child once but no hospitalization.

Sever/frequently sick stands for the sickness of mother on the pregnancy of the index child once and leads to hospitalization or more than one-time sick health experience.

2.6. Ethical Clearance. Ethical clearance (Ref. No. 009/2009) was obtained from Dilla University, College of Medicine and Health Sciences research review board (IRB), and a support letter from the school of Public Health was submitted to the Gedeo Zone Health Department and Wonago District health office, and permission was also obtained. The purpose of the study was explained to the mothers, and written consent was obtained from them. They were reassured about the safety of the procedure and maintaining confidentiality about the data they gave.

\section{Results}

A total of 3324 children who were aged 2-5 years during the deworming campaign from three kebeles, namely, Hasse Haro $(n=983)$, Mokonissa $(n=1310)$, and Wonago $(n=1031)$ were included. The mean age of mothers of index child $(n=3256)$ was 30 years $( \pm S D=5.72)$, many of them (95\%) were married, 90\% were Gedeo, 92.8\% were protestant followers, and $88.9 \%$ were Gede-uffa speakers. The mean age of fathers of index child $(n=3114)$, who were the household heads, was 38 years $( \pm \mathrm{SD}=8.71)$. Most of the study participants lived in rural kebeles (86\%), in a nuclear type of family (88\%), and a family size of 5-7 (55\%). A large number of mothers (74\%) and fathers (47\%) had no formal education while large numbers of mothers (77\%) and fathers (71\%) were housewives and farmers, respectively. About $94 \%$ of households' heads were male in which $92 \%$ of household heads' relationship with the child is being a father. The average household monthly income was 555 Ethiopian birr, and their main source of food (76\%) was mainly from their farming. The majority of the household heads (96\%) own their plot of land whereas only $27 \%$ of them own livestock (Table 1).

About $57 \%$ of children in the study areas were born at home, while $41 \%$ were in a health institution and $0.5 \%$ was in other places. The mean birth order of the index children was $3( \pm S D=1.64)$. Most index children $(92 \%)$ were born before the $6^{\text {th }}$ birth order. The mean birth interval of the index children was 2 years $( \pm \mathrm{SD}=0.94)$. Slightly above half of the index children (53\%) had $\leq 2$ years of the birth interval from their preceding siblings. The majority of the index children $(84 \%)$ had a sibling whose age is less than 5 years. Above two-thirds of index children (68\%) got baby bath twice or more per week whereas $31 \%$ of the children have got once per week or not at all. The majority of children $(81 \%)$ were previously dewormed, at least once. Moreover, almost all children (99\%) ever took Bacillus Calmette-Guérin vaccine (BCG); polio 0, 1, 2; Penta 1, 2, 3, and measles vaccines. Besides, about a small number of children (6\%) took another type of vaccine. Some of the children had an episode of illnesses in the previous two weeks just before baselines such as diarrhea (6\%), acute respiratory infection (ARI) (5\%), and fever (11\%) (Table 1).

Above three-quarters of children (79\%) feed three or more times per day. A large number of children breastfed for two or more years whereas there were no special prelacteal feeding practices in the study area. The mean period of exclusive breastfeeding was 5 months $( \pm S D=1.78)$. The children were exclusively breastfed either for less than six months (49\%), for exactly six months (32\%), or greater than six months (18\%). After six months, children who got supplementary food by spoon-feeding were $45 \%$. Less than half of the mothers of index children (42\%) fed with extra food during pregnancy of the index child (Table 2).

The mean age of children was 40 months $( \pm S D=10.5)$; the mean weight was $12.64 \mathrm{~kg}( \pm \mathrm{SD}=2.37)$; and the mean height was $89.48 \mathrm{~cm}( \pm \mathrm{SD}=9.34)$. The majority $(77 \%)$ of children were well-nourished, and about $13 \%$ of children were wasted. 
TABLE 1: Child's birth-related and health care characteristics in previous two weeks before the interview of the index child in Wonago district from December $19^{\text {th }}$ to $23^{\text {th }}(n=3273)$.

\begin{tabular}{|c|c|}
\hline Variable & Frequency $N(\%)$ \\
\hline Place of birth of the child & $3273(100)$ \\
\hline Home & $1886(57.6)$ \\
\hline Health institution & $1372(41.9)$ \\
\hline Other & $15(0.5)$ \\
\hline Child's birth order group & $3273(100)$ \\
\hline$<6$ & $3037(92.8)$ \\
\hline$\geq 6$ & $236(7.2)$ \\
\hline Mean $( \pm S D)$ & $2.94(1.64)$ \\
\hline Birth interval category preceding the child & $2562(100)$ \\
\hline$\leq 2$ years & $1364(53.2)$ \\
\hline$>2$ years & $1198(46.8)$ \\
\hline Mean $( \pm S D)$ & $2.43(0.94)$ \\
\hline No. of U5 other than the child & $1684(100)$ \\
\hline 1 child & $1420(84.3)$ \\
\hline$>1$ child & $264(15.7)$ \\
\hline Mean $( \pm S D)$ & $0.6(0.65)$ \\
\hline Current deworming status of the child & $3273(100)$ \\
\hline Yes & $3273(100)$ \\
\hline No & $0(0.0)$ \\
\hline Previous deworming frequency & $3273(100)$ \\
\hline 0 & $606(18.5)$ \\
\hline 1 & $417(12.7)$ \\
\hline 2 & $912(27.9)$ \\
\hline 3 & $1306(39.9)$ \\
\hline 4 & $32(1.0)$ \\
\hline Mean $( \pm S D)$ & $1.92(1.14)$ \\
\hline Any type of vaccine experience & $3273(100)$ \\
\hline Yes & $3273(100)$ \\
\hline No & $0(0.0)$ \\
\hline BCG & $3273(100)$ \\
\hline Yes & $3256(99.5)$ \\
\hline No & $17(0.5)$ \\
\hline Polio $_{0}$ & $3273(100)$ \\
\hline Yes & $3256(99.5)$ \\
\hline No & $17(0.5)$ \\
\hline Polio $_{1}$ & $3273(100)$ \\
\hline Yes & $3256(99.5)$ \\
\hline No & $17(0.5)$ \\
\hline Polio $_{2}$ & $3273(100)$ \\
\hline Yes & $3256(99.5)$ \\
\hline No & $17(0.5)$ \\
\hline Penta $_{1}$ & $3273(100)$ \\
\hline Yes & $3255(99.5)$ \\
\hline No & $18(0.5)$ \\
\hline Penta $_{2}$ & $3273(100)$ \\
\hline Yes & $3255(99.5)$ \\
\hline No & $18(0.5)$ \\
\hline
\end{tabular}

TABLE 1: Continued.

\begin{tabular}{lc}
\hline Variable & Frequency $N(\%)$ \\
\hline Penta $_{3}$ & $3273(100)$ \\
Yes & $3255(99.5)$ \\
No & $17(0.5)$ \\
Measles & $3273(100)$ \\
Yes & $3244(99.1)$ \\
No & $29(0.9)$ \\
Any other type of vaccine & $3273(100)$ \\
Yes & $210(6.4)$ \\
No & $3063(93.6)$ \\
Diarrhea experience & $3273(100)$ \\
Yes & $197(6.0)$ \\
No & $3076(94.0)$ \\
ARI experience & $3273(100)$ \\
Yes & $188(5.7)$ \\
No & $3085(94.3)$ \\
Fever experience & $3273(100)$ \\
Yes & $362(11.1)$ \\
No & $2911(88.9)$ \\
\hline
\end{tabular}

$N$ : number; SD: standard deviation; BCG: Bacillus Calmette-Guérin vaccine; Penta: diphtheria, pertussis, tetanus vaccine; ARI: acute respiratory infection.

3.1. Factors Associated with Wasting. Children residing in urban settings were 1.77 times more likely $[\mathrm{AOR}=1.77$ (95\% CI: 1.35, 2.32)] to be wasted than rural residents. Children whose household heads' age is greater than 37 years were 1.25 times more likely $[\mathrm{AOR}=1.25$ (95\% CI: 1.01 , 1.55)] to be wasted than children with household heads' age equal to 37 and fewer years. Children who were among the extended family were 1.52 times more likely [AOR $=1.52$ $(95 \%$ CI: $1.13,2.05)]$ to be wasted than those who lived in a nuclear family.

Merchant mother's children were 1.48 times more likely [AOR $=1.48$ (95\% CI: 1.05, 2.08)] to be wasted than housewife mothers. Children whose fathers are governmentemployed were 1.93 times more likely [AOR $=1.93(95 \%$ CI: $1.08,3.46)]$ to be wasted than those whose father's occupation was farmers. Family decisions made by other than family members like aunt and uncle were 2.56 times more likely $[\mathrm{AOR}=2.56(95 \% \mathrm{CI}: 1.00,6.52)]$ to be wasted than those made by the father. Children from households without land were 1.61 times more likely $[\mathrm{AOR}=1.61$ (95\% CI: 1.01 , 2.59)] to be wasted than children with households of their own. Children who live in households with livestock were 1.27 times more likely [AOR $=1.27$ (95\% CI: $1.00,1.59)$ ] to be wasted than those living in households that had no livestock.

Children whose age is between 36-47 months and 48-59 months were $1.36[\mathrm{AOR}=1.36(95 \% \mathrm{CI}: 1.04,1.78)]$ and 1.46 times more likely $[\mathrm{AOR}=1.46(95 \% \mathrm{CI}: 1.01,2.09)]$ to be wasted, respectively, than children whose age was between 24 and 35 months. Being a male child was 1.42 times more likely $[\mathrm{AOR}=1.42(95 \% \mathrm{CI}: 1.07,1.88)]$ to be wasted than females. Children whose birth interval was $>2$ years were 
TABLE 2: Feeding practices of the index child and mothers during pregnancy of the index child, in Wonago district from December $19^{\text {th }}$ to $23^{\text {th }}(n=3273)$.

\begin{tabular}{lc}
\hline Variable & Frequency $N^{*}(\%)$ \\
\hline Frequency of daily meal & $3273(100)$ \\
$\geq 3$ & $2601(79.5)$ \\
$<3$ & $672(20.5)$ \\
Mean $( \pm$ SD) & $2.85(0.57)$ \\
Years of GBF & $3273(100)$ \\
$\geq 2$ years & $2876(87.9)$ \\
$<2$ years & $397(12.1)$ \\
Mean $( \pm$ SD) & $2.1(0.59)$ \\
Prelacteal feeding experience & $3273(100)$ \\
Yes & $3273(100)$ \\
No & $0(0.0)$ \\
No. of months for EBF & $3273(100)$ \\
$<6$ months & $1610(49.2)$ \\
6 months & $1070(32.7)$ \\
$>6$ months & $593(18.1)$ \\
Mean $( \pm$ SD) & $5.4(1.78)$ \\
Mechanism of feeding & $3273(100)$ \\
Bottle & $317(9.7)$ \\
Cup & $1245(38.0)$ \\
Spoon & $1482(45.3)$ \\
Other & $229(7.0)$ \\
Use of extra food on pregnancy & $3256(100)$ \\
Yes & $1388(42.6)$ \\
No & $1868(57.4)$ \\
\hline
\end{tabular}

$N$ : number; SD: standard deviation; GBF: general breastfeeding; EBF: exclusive breastfeeding.

$27 \%$ less likely to be $[\mathrm{AOR}=0.73$ (95\% CI: $0.55,0.98)]$ wasted than whose birth interval was $\leq 2$ years (Table 3 ).

Children who did not take Penta ${ }_{1}$ and Penta vaccines $_{2}$ were 3 times more likely [AOR $=3.01$ (95\% CI: 1.07, 8.48)] to be wasted than those who took the vaccine. Similarly, children who took other types such as the Rotavirus and pneumococcal congested vaccine were 1.62 times more likely $[\mathrm{AOR}=1.62(95 \% \mathrm{CI}: 1.10,2.36)]$ to be wasted than those who did not take other types. Children who had a diarrheal disease in the past two weeks from the study period were found to have $61 \%$ less likely [AOR $=0.39$ (95\% CI: 0.17 , 0.90)] to be wasted when compared to those who did not have the disease. Children's feeding mechanism of additional food using a bottle were 1.8 times more likely [AOR $=1.80$ $(95 \%$ CI: 1.08, 3.01)] to be wasted than those whose way of feeding was using the hand.

Children whose mothers' $\mathrm{BMI}<18.5 \mathrm{~kg} / \mathrm{m}^{2}$ were 1.28 times more likely $[\mathrm{AOR}=1.28$ (95\% CI: $1.03,1.59)]$ to be wasted than children whose mothers' $\mathrm{BMI} \geq 18.5 \mathrm{~kg} / \mathrm{m}^{2}$. Children whose mothers attended at least 1 ANC follow-up were $33 \%$ less likely $[\mathrm{AOR}=0.67$ (95\% CI: $0.46,0.98)]$ to be wasted than those whose mothers' ANC follow-up was 4 and above. Children who had less than two times bathing per week were 1.4 times more likely [AOR $=1.42(95 \%$ CI: $1.03,1.96)]$ to be wasted than those with two and greater times bathing per week (Table 4).

\section{Discussion}

The study was aimed at assessing the magnitude and associated factors of wasting among children 2-5 years in Wonago district, southern Ethiopia. The study found that most, 77\%, of the children were well-nourished and about $13 \%$ of children were wasted.

Despite the results observed and ongoing attempts which have been done towards ensuring and minimizing under-five malnutrition, Ethiopia is still facing undernutrition as a major health problem. The result of the current study also revealed that the percent of wasted children was above the national level reported by Ethiopian Demographic Health Survey (EMDHS) 2014, and EDHS 2016 data, respectively $[20,22]$. This holds with regional levels too, which might be due to sample size variation.

The result of this study shows that children of government-employed fathers have an increased likelihood of being wasted than children of a farmer. This can be discussed as farm work makes fathers more familiar with food products and to be concerned about food consumption of children whereas government-employed fathers are far away from food concerns.

For the current study, the age group of children of 48-59 months was found to have an increased risk of wasting than 24-35-month age group children. This may be for the reason of the mobile nature of the children in the age group of 48-59 months and the need for high energy requirements. Being a male child has also increased the likelihood of wasting than females in this study which shows a consistent finding with the study in Haramaya district, eastern Ethiopia [23]. This is probably due to the fact that boys are involved in more energy-consuming tasks than girls.

Children who have diarrheal disease were found to be less likely to develop wasting than their counterparts. This result contradicts with the study on Bule Hora and Somalia which states that diarrheal disease experienced by children in the past two weeks before the data collection was an independent determinant factor for wasting to be developed $[24,25]$. This may be due to the community trend variation in emphasizing for diseased children which helped them to reduce wasting.

In the current study, children with less bathing frequency per week were found to be more wasted as compared to those children with more frequent bathing. The reason for this might be due to inadequate sanitation that increases the probability of infectious diseases, which indirectly can cause malnutrition. This result may be argued since as the frequency of sanitation increases, the nutritional wellbeing of the child increases.

4.1. Strength and Limitation. This study collected data from all participants rather than sampling which increased the precision of estimates. The study collected information by questionnaire and anthropometric measures with daily calibration to minimize potential information bias. This study 
TABLE 3: A bivariable and multivariable logistic regression model for determinants of wasting among children aged 2-5 years in Wonago district $(n=3273)$.

\begin{tabular}{|c|c|c|c|c|c|}
\hline \multirow{2}{*}{ Variables } & & \multicolumn{2}{|c|}{ WHZ } & \multirow{2}{*}{ COR $(95 \% \mathrm{CI})$} & \multirow{2}{*}{ AOR $(95 \% \mathrm{CI})$} \\
\hline & & Wasted & Not wasted & & \\
\hline \multirow{2}{*}{ Age of the mother } & $<30$ years & 160 & 1397 & $0.81(0.65,1.01)$ & $0.87(0.58,1.31)$ \\
\hline & $\geq 30$ years & 209 & 1478 & & \\
\hline \multirow{4}{*}{ Marital status of the mother } & Married & 353 & 2740 & & \\
\hline & Single & 1 & 16 & $0.49(0.07,3.67)$ & \\
\hline & Widowed & 6 & 60 & $0.78(0.33,1.81)$ & \\
\hline & Divorced & 9 & 59 & $1.18(0.58,2.41)$ & \\
\hline \multirow{4}{*}{ Ethnic group of the mother } & Gedeo & 331 & 2607 & & \\
\hline & Oromo & 23 & 172 & $1.05(0.67,1.65)$ & \\
\hline & Amhara & 6 & 46 & $1.03(0.44,2.42)$ & \\
\hline & Others & 9 & 50 & $1.42(0.69,2.91)$ & \\
\hline \multirow{3}{*}{ Religion of the mother } & Protestant & 332 & 2677 & & \\
\hline & Orthodox & 36 & 182 & $1.59(1.09,2.32)$ & $0.99(0.51,1.91)$ \\
\hline & Others & 1 & 16 & $0.50(0.07,3.81)$ & $0.36(0.04,3.15)$ \\
\hline \multirow{3}{*}{ Language of the mother } & Gede-uffa & 320 & 2564 & & \\
\hline & Amharic & 44 & 199 & $1.77(1.25,2.51)$ & $1.16(0.57,2.36)$ \\
\hline & Others & 5 & 112 & $0.36(0.15,0.88)$ & $0.29(0.09,0.96)$ \\
\hline \multirow{2}{*}{ Age group of father } & $\leq 37$ years & 166 & 1425 & & \\
\hline & $>37$ years & 188 & 1323 & $1.22(0.98,1.52)$ & $0.19(0.01,4.26)$ \\
\hline \multirow{2}{*}{ HHH's age group } & $\leq 37$ years & 177 & 1530 & & \\
\hline & $>37$ years & 196 & 1358 & $1.25(1.01,1.55)$ & $6.52(0.29,146.70)$ \\
\hline \multirow{2}{*}{ Residence of $\mathrm{HH}$} & Rural & 295 & 2512 & & \\
\hline & Urban & 78 & 376 & $1.77(1.35,2.32)$ & $1.91(0.94,3.89)$ \\
\hline \multirow{2}{*}{ Type of family } & Nuclear & 312 & 2559 & & \\
\hline & Extended & 61 & 329 & $1.52(1.13,2.05)$ & $1.16(0.72,1.86)$ \\
\hline \multirow{4}{*}{ Family size category } & $2-4$ & 109 & 923 & $0.50(0.23,1.11)$ & $1.18(0.39,3.57)$ \\
\hline & $5-7$ & 214 & 1594 & $0.57(0.26,1.25)$ & $1.17(0.43,3.17)$ \\
\hline & $8-10$ & 42 & 337 & $0.53(0.23,1.22)$ & $0.88(0.32,2.44)$ \\
\hline & $>10$ & 8 & 34 & & \\
\hline \multirow{4}{*}{ Educational level of the mother } & No formal education & 269 & 2144 & & \\
\hline & Primary & 87 & 623 & $1.11(0.86,1.44)$ & \\
\hline & Secondary & 11 & 99 & $0.89(0.47,1.67)$ & \\
\hline & Above secondary & 2 & 9 & $1.77(0.38,8.24)$ & \\
\hline \multirow{5}{*}{ Mothers' occupation } & Housewife & 269 & 2246 & & \\
\hline & Farmer & 46 & 319 & $1.20(0.86,1.68)$ & $1.31(0.81,2.11)$ \\
\hline & Merchant & 44 & 249 & $1.48(1.05,2.08)$ & $1.31(0.79,2.15)$ \\
\hline & Government employee & 1 & 25 & $0.33(0.05,2.48)$ & $0.54(0.06,4.57)$ \\
\hline & Others & 9 & 36 & $2.09(0.99,4.38)$ & $2.64(0.89,7.81)$ \\
\hline \multirow{4}{*}{ The educational level of the father } & No formal education & 161 & 1303 & & \\
\hline & Primary & 135 & 975 & $1.12(0.88,1.43)$ & \\
\hline & Secondary & 45 & 394 & $0.92(0.65,1.31)$ & \\
\hline & Above secondary & 13 & 76 & $1.38(0.75,2.55)$ & \\
\hline \multirow{2}{*}{ Fathers occupation } & Farmer & 241 & 1989 & & \\
\hline & Merchant & 58 & 463 & $1.03(0.76,1.40)$ & $0.97(0.64,1.46)$ \\
\hline
\end{tabular}


TABle 3: Continued.

\begin{tabular}{|c|c|c|c|c|c|}
\hline \multirow{2}{*}{ Variables } & & \multicolumn{2}{|c|}{ WHZ } & \multirow{2}{*}{ COR $(95 \% \mathrm{CI})$} & \multirow{2}{*}{ AOR (95\% CI) } \\
\hline & & Wasted & Not wasted & & \\
\hline & Government employee & 26 & 116 & $1.85(1.18,2.89)$ & $1.93(1.08,3.46)$ \\
\hline & Others & 29 & 180 & $1.33(0.88,2.01)$ & $0.70(0.38,1.30)$ \\
\hline \multirow{2}{*}{ HHH's sex } & Male & 353 & 2741 & & \\
\hline & Female & 20 & 147 & $1.06(0.65,1.71)$ & \\
\hline \multirow{4}{*}{ HHH's r/p with the child } & Father & 336 & 2682 & & \\
\hline & Mother & 19 & 127 & $1.19(0.73,1.96)$ & $1.22(0.24,6.17)$ \\
\hline & Caregiver & 13 & 59 & $1.76(0.96,3.24)$ & $1.02(0.41,2.56)$ \\
\hline & Other & 5 & 20 & $1.99(0.74,5.35)$ & $1.56(0.13,19.35)$ \\
\hline \multirow{2}{*}{ HH's monthly income } & $\leq 500$ birr & 212 & 1555 & & \\
\hline & $>500$ birr & 161 & 1333 & $0.89(0.71,1.10)$ & \\
\hline \multirow{4}{*}{ Family decision maker } & Father & 210 & 1612 & & \\
\hline & Mother & 40 & 241 & $1.27(0.89,1.83)$ & $1.79(0.91,3.56)$ \\
\hline & Both & 117 & 1017 & $0.88(0.69,1.12)$ & $1.23(0.89,1.69)$ \\
\hline & Other & 6 & 18 & $2.56(1.00,6.52)$ & $1.29(0.13,12.68)$ \\
\hline \multirow{3}{*}{ HH's source of food } & Agricultural products & 274 & 2201 & & \\
\hline & Purchase & 98 & 681 & $1.16(0.90,1.48)$ & $0.76(0.47,1.23)$ \\
\hline & Others & 1 & 6 & $1.34(0.16,11.16)$ & \\
\hline \multirow{2}{*}{ HH's land ownership } & Yes & 351 & 2780 & & \\
\hline & No & 22 & 108 & $1.61(1.01,2.59)$ & $1.14(0.53,2.45)$ \\
\hline \multirow{2}{*}{ HH's livestock ownership } & Yes & 118 & 773 & $1.27(1.00,1.59)$ & $1.21(0.87,1.69)$ \\
\hline & No & 255 & 2115 & & \\
\hline \multirow{3}{*}{ Age group of the child before } & 24-35 months & 109 & 1079 & & \\
\hline & 36-47 months & 128 & 931 & $1.36(1.04,1.78)$ & $1.09(0.76,1.57)$ \\
\hline & 48-59 months & 136 & 878 & $1.53(1.17,2.00)$ & $1.46(1.01,2.09)$ \\
\hline \multirow{2}{*}{ Sex of the child } & Female & 173 & 1605 & & \\
\hline & Male & 200 & 1283 & $1.45(1.17,1.79)$ & $1.42(1.07,1.88)$ \\
\hline \multirow{2}{*}{ Place of birth of the child } & Home & 208 & 1683 & & \\
\hline & Health institution & 165 & 1205 & $1.11(0.89,1.38)$ & \\
\hline \multirow{2}{*}{ Child's birth order group } & $<6$ & 348 & 2678 & & \\
\hline & $\geq 6$ & 25 & 210 & $0.92(0.59,1.41)$ & \\
\hline \multirow{2}{*}{ Birth interval category preceding the child } & $\leq 2$ years & 184 & 1175 & & \\
\hline & $>2$ years & 120 & 1075 & $0.71(0.56,0.91)$ & $0.73(0.55,0.98)$ \\
\hline \multirow{2}{*}{ No. of U5 other than the child } & 1 child & 158 & 1255 & & \\
\hline & $>1$ child & 30 & 232 & $1.03(0.68,1.56)$ & \\
\hline
\end{tabular}

WHZ: weight-for-height $z$-score; COR: crude odds ratio; AOR: adjusted odds ratio; CI: confidence interval; HH: household; HHH: household head; r/p: relationship; No: number. 
TABLE 4: A multivariable logistic regression model for determinants of wasting among children aged 2-5 years in Wonago district $(n=3273)$.

\begin{tabular}{|c|c|c|c|c|c|}
\hline \multirow{2}{*}{ Variables } & & \multicolumn{2}{|c|}{ WHZ } & \multirow{2}{*}{ COR $(95 \%$ CI $)$} & \multirow{2}{*}{ AOR $(95 \% \mathrm{CI})$} \\
\hline & & Wasted & Not wasted & & \\
\hline \multirow{5}{*}{ Previous deworming frequency } & 0 & 34 & 572 & $0.58(0.17,1.98)$ & \\
\hline & 1 & 49 & 366 & $1.29(0.38,4.41)$ & \\
\hline & 2 & 120 & 788 & $1.47(0.44,4.91)$ & \\
\hline & 3 & 167 & 1133 & $1.43(0.43,4.73)$ & \\
\hline & 4 & 3 & 29 & & \\
\hline \multirow{2}{*}{ BCG } & Yes & 369 & 2874 & & \\
\hline & No & 4 & 13 & $2.23(0.73,6.79)$ & $0.79(0.12,5.14)$ \\
\hline \multirow{2}{*}{ Polio $_{0}$} & Yes & 370 & 2875 & & \\
\hline & No & 4 & 13 & $1.79(0.51,6.32)$ & \\
\hline \multirow{2}{*}{ Polio $_{1}$} & Yes & 370 & 2874 & & \\
\hline & No & 3 & 14 & $1.66(0.48,5.82)$ & \\
\hline \multirow{2}{*}{$\mathrm{Polio}_{2}$} & Yes & 370 & 2874 & & \\
\hline & No & 3 & 14 & $1.66(0.48,5.82)$ & \\
\hline \multirow{2}{*}{ Penta $_{1}$} & Yes & 368 & 2875 & & \\
\hline & No & 5 & 13 & $3.01(1.07,8.48)$ & $4.54(0.09,214.49)$ \\
\hline \multirow{2}{*}{ Penta $_{2}$} & Yes & 368 & 2875 & & \\
\hline & No & 5 & 13 & $3.01(1.07,8.48)$ & \\
\hline \multirow{2}{*}{ Penta $_{3}$} & Yes & 369 & 2875 & & \\
\hline & No & 4 & 13 & $2.39(0.78,7.39)$ & $0.74(0.01,42.33)$ \\
\hline \multirow{2}{*}{ Measles } & Yes & 367 & 2865 & & \\
\hline & No & 6 & 33 & $2.04(0.82,5.03)$ & $2.11(0.56,7.97)$ \\
\hline \multirow{2}{*}{ Any other type of vaccine } & Yes & 35 & 174 & $1.62(1.10,2.36)$ & $1.03(0.54,1.98)$ \\
\hline & No & 338 & 2714 & & \\
\hline \multirow{2}{*}{ Diarrhea experience } & Yes & 17 & 180 & $0.72(0.43,1.19)$ & $0.39(0.17,0.90)$ \\
\hline & No & 356 & 2708 & & \\
\hline \multirow{2}{*}{ ARI experience } & Yes & 20 & 168 & $0.92(0.57,1.48)$ & \\
\hline & No & 353 & 2720 & & \\
\hline \multirow{2}{*}{ Fever experience } & Yes & 41 & 321 & $0.99(0.70,1.39)$ & \\
\hline & No & 332 & 2567 & & \\
\hline \multirow{2}{*}{ Frequency of daily meal } & $\geq 3$ & 310 & 2279 & & \\
\hline & $<3$ & 63 & 609 & $0.76(0.57,1.01)$ & $0.96(0.64,1.43)$ \\
\hline \multirow{2}{*}{ No. of years for GBF } & $\geq 2$ years & 318 & 2546 & & \\
\hline & $<2$ years & 55 & 342 & $1.29(0.95,1.75)$ & $1.01(0.67,1.51)$ \\
\hline \multirow{3}{*}{ No. of months for EBF } & $<6$ months & 189 & 1414 & & \\
\hline & 6 months & 115 & 951 & $0.91(0.71,1.16)$ & \\
\hline & $>6$ months & 69 & 523 & $0.99(0.74,1.32)$ & \\
\hline \multirow{4}{*}{ Mechanism of feeding } & Bottle & 55 & 261 & $1.80(1.08,3.01)$ & $1.40(0.65,3.02)$ \\
\hline & Cup & 142 & 1096 & $1.11(0.70,1.75)$ & $1.36(0.69,2.64)$ \\
\hline & Spoon & 152 & 1326 & $0.98(0.62,1.54)$ & $1.26(0.65,2.43)$ \\
\hline & Hand & 24 & 205 & & \\
\hline \multirow{2}{*}{ Use of extra food on pregnancy } & Yes & 141 & 1244 & $0.81(0.65,1.01)$ & $1.06(0.75,1.50)$ \\
\hline & No & 228 & 1631 & & \\
\hline BMI & $\geq 18.5 \mathrm{~kg} / \mathrm{m}^{2}$ & 213 & 1830 & & \\
\hline
\end{tabular}


TABLE 4: Continued.

\begin{tabular}{|c|c|c|c|c|c|}
\hline \multirow{2}{*}{ Variables } & & \multicolumn{2}{|c|}{ WHZ } & \multirow{2}{*}{ COR $(95 \%$ CI $)$} & \multirow{2}{*}{$\operatorname{AOR}(95 \% \mathrm{CI})$} \\
\hline & & Wasted & Not wasted & & \\
\hline & $<18.5 \mathrm{~kg} / \mathrm{m}^{2}$ & 156 & 1045 & $1.28(1.03,1.59)$ & $1.23(0.92,1.65)$ \\
\hline \multirow{3}{*}{ Health status } & Frequently sick & 7 & 57 & $0.99(0.45,2.19)$ & $0.76(0.28,2.07)$ \\
\hline & Sometimes sick & 78 & 523 & $1.21(0.92,1.58)$ & $1.41(0.98,2.02)$ \\
\hline & No sickness & 284 & 2295 & & \\
\hline \multirow{5}{*}{ No. of ANC visit } & 0 & 76 & 589 & $0.89(0.64,1.24)$ & $0.89(0.57,1.38)$ \\
\hline & 1 & 47 & 480 & $0.67(0.46,0.98)$ & $0.69(0.42,1.15)$ \\
\hline & 2 & 109 & 767 & $0.98(0.72,1.33)$ & $0.94(0.62,1.44)$ \\
\hline & 3 & 55 & 475 & $0.79(0.55,1.15)$ & $0.79(0.49,1.29)$ \\
\hline & $\geq 4$ & 82 & 564 & & \\
\hline \multirow{2}{*}{ FP methods information } & Yes & 322 & 2558 & & \\
\hline & No & 47 & 317 & $1.18(0.85,1.63)$ & \\
\hline \multirow{2}{*}{ If yes, have you ever use it } & Yes & 286 & 2212 & & \\
\hline & No & 36 & 346 & $0.97(0.75,1.26)$ & \\
\hline \multirow{2}{*}{ No. of bathing the child/week } & $\geq 2$ & 242 & 2000 & & \\
\hline & $<2$ & 131 & 888 & $1.22(0.97,1.53)$ & $1.42(1.03,1.96)$ \\
\hline \multirow{2}{*}{ Mothers handwashing after using toilet } & Yes & 318 & 2423 & & \\
\hline & No & 51 & 452 & $0.86(0.63,1.18)$ & \\
\hline \multirow{2}{*}{ Mothers handwashing before meal preparation or serving } & Yes & 361 & 2811 & & \\
\hline & No & 8 & 64 & $0.97(0.46,2.05)$ & \\
\hline \multirow{3}{*}{ HH's drinking water source } & Well & 173 & 1320 & & \\
\hline & Pipe & 166 & 1204 & $1.05(0.84,1.32)$ & $0.82(0.55,1.20)$ \\
\hline & Surface water & 34 & 364 & $0.71(0.49,1.05)$ & $0.76(0.43,1.34)$ \\
\hline \multirow{2}{*}{ HH's window availability } & Yes & 298 & 2240 & & \\
\hline & No & 75 & 648 & $0.87(0.67,1.14)$ & \\
\hline \multirow{4}{*}{ HH's condition of floor } & Earth & 328 & 2626 & & \\
\hline & Dung & 2 & 10 & $1.60(0.35,7.34)$ & $0.00(0.00)$ \\
\hline & Cement & 15 & 90 & $1.33(0.76,2.33)$ & $0.98(0.44,2.17)$ \\
\hline & Bamboo & 28 & 162 & $1.38(0.91,2.10)$ & $1.07(0.54,2.14)$ \\
\hline \multirow{2}{*}{ HH's toilet availability } & Yes & 313 & 2393 & & \\
\hline & No & 60 & 495 & $0.93(0.63,1.24)$ & \\
\hline \multirow{4}{*}{ If yes, what type of toilet is it } & Open-pit & 269 & 2064 & & \\
\hline & Bush/field & 19 & 198 & $0.74(0.45,1.19)$ & $0.66(0.37,1.19)$ \\
\hline & Pit with slab & 19 & 105 & $1.39(0.84,2.30)$ & $0.97(0.49,1.89)$ \\
\hline & VIP & 6 & 26 & $1.77(0.72,4.34)$ & $1.35(0.43,4.26)$ \\
\hline \multirow{2}{*}{ HH's garbage disposal pit availability } & Yes & 128 & 849 & $1.26(0.99,1.58)$ & $1.03(0.72,1.47)$ \\
\hline & No & 245 & 2039 & & \\
\hline \multirow{2}{*}{ HH's distance from the nearest health care service in $\mathrm{km}$} & $>8.77 \mathrm{~km}$ & 171 & 1300 & $1.03(0.83,1.28)$ & \\
\hline & $\leq 8.77 \mathrm{~km}$ & 202 & 1588 & & \\
\hline
\end{tabular}

WHZ: weight-for-height $z$-score; COR: crude odds ratio; AOR: adjusted odds ratio; CI: confidence interval; BCG: Bacillus Calmette-Guérin vaccine; Penta: diphtheria, pertussis, tetanus, haemophilus influenza type B, hepatitis B vaccine; ARI: acute respiratory infection; No: number; GBF: general breastfeeding; EBF: exclusive breastfeeding; BMI: body mass index; ANC: antenatal care; FP: family planning; HH: household; VIP: ventilated pit latrine; km: kilometer.

also has limitations. First, laboratory investigation and related data were not collected in this study. Second, other unmeasured confounders or residual confounders could play by inflating or underestimating the reported findings; multilevel modeling was not done. Finally, still, some measurement errors and recall biases could exist among 
respondents answering questions relating to events happening in the past.

\section{Conclusion}

The proportion of wasting was higher as compared to the national figure. Child, maternal, paternal, or environmental-related factors were significantly associated with child nutritional status. It was also found that government-employed fathers, child age group 48-59 months, being a male child, having the diarrheal disease in past two weeks before the data collection, and bathing frequency below two times per week were significant determinant variables of wasting for children with the 24-59month age group. There is a need to focus on other causes like feeding less nourishing foods. Having a better sanitation habit is recommended. The age of the child has a significant effect on wasting. Hence, attention is needed on the education of child age-specific feeding and child care interventions.

\section{Data Availability}

Data will be available upon request from the corresponding author.

\section{Ethical Approval}

Ethical clearance was obtained from the Ethical Review Board of Dilla University, College of Medical and Health Science. A letter of permission was obtained from the Wonago health office before the data collection. There was no invasive procedure in the data collection process. After, the purpose of the study was explained to the mothers and written consent was obtained from them. The right of participants to withdraw from the study at any time was respected without any precondition. Moreover, the confidentiality of information obtained was guaranteed by all data collectors and investigators by using code numbers. Children who fulfilled the criteria for malnutrition were referred to the respective rehabilitation centers.

\section{Conflicts of Interest}

The authors declare that they have no competing interests.

\section{Authors' Contributions}

All authors participated in the conception, design, data analysis, drafting, or revising of the article and gave final approval of the version to be published. All authors agree to be accountable for all aspects of the work.

\section{Acknowledgments}

We would like to express our deepest gratitude to Dilla University, the College of Medicine and Health Science institutional review board (IRB), for the ethical clearance. Our gratitude also extends to the staff of the Gedeo zone Health Bureau and Wonago district health office for their collaboration. We would like to thank the data collectors, supervisors, and all study participants who spent their fruitful time for the accomplishment of this study.

\section{References}

[1] FMOH and WHO, Ethiopian Guidelines for the Management of Common Illnesses in Hospitals: Pediatric Hospital Care, 1st, 2010.

[2] B. Kanjilal, P. Mazumdar, M. Mukherjee, and M. H. Rahman, "Nutritional status of children in India: household socioeconomic condition as the contextual determinant," International Journal for Equity in Health, vol. 9, no. 1, p. 19, 2010.

[3] M. Sassi, Child nutritional status in the Malawian District of Salima: a capability approach, 2013.

[4] S. R. Howlader, K. Sethuraman, F. Begum, D. Paul, A. E. Sommerfelt, and T. Kovach, the Office of Health, Infectious Diseases, and Nutrition, Bureau for Global Health, United States Agency for International Development (USAID), and USAID/Bangladesh under terms of Cooperative Agreement No. AIDOAA-A-12-00005, through the Food and Nutrition Technical Assistance III Project (FANTA), managed by FHI 360. The contents are the responsibility of FHI 360 and do not necessarily reflect the views of USAID or., Food and Nutrition Technical Assistance III Project (FANTA), FHI 360, 2012.

[5] R. E. Black, L. H. Allen, Z. A. Bhutta et al., "Maternal and child undernutrition: global and regional exposures and health consequences," The Lancet, vol. 371, no. 9608, pp. 243-260, 2008.

[6] S. S. Morris, B. Cogill, and R. Uauy, "Effective international action against undernutrition: why has it proven so difficult, and what can be done to accelerate progress?," The Lancet, vol. 371, no. 9612, pp. 608-621, 2008.

[7] WHO Working Group, "Use, and interpretation of anthropometric indicators of nutritional status," Bulletin of the World Health Organization, vol. 64, no. 6, p. 929, 1986.

[8] R. E. Black, K. H. Brown, and S. Becker, "Malnutrition is a determining factor in diarrheal duration, but not incidence, among young children in a longitudinal study in rural Bangladesh," The American Journal of Clinical Nutrition, vol. 39, no. 1, pp. 87-94, 1984.

[9] H. L. Delgado, V. Valverde, J. M. Belizan, and R. E. Klein, "Diarrheal diseases, nutritional status, and health care: analyses of their interrelationships," Ecology of Food and Nutrition, vol. 12, no. 4, pp. 229-234, 1983.

[10] A. Tomkins, "Nutritional status and severity of diarrhoea among pre-school children in rural Nigeria," The Lancet, vol. 317, no. 8225, pp. 860-862, 1981.

[11] L. C. Chen, A. A. Chowdhury, and S. L. Huffman, "Anthropometric assessment of energy-protein malnutrition and subsequent risk of mortality among preschool-aged children," The American Journal of Clinical Nutrition, vol. 33, no. 8, pp. 1836-1845, 1980.

[12] V. Vella, A. Tomkins, A. Borghesi, G. B. Migliori, J. Ndiku, and B. C. Adriko, "Anthropometry and childhood mortality in northwest and southwest Uganda," American Journal of Public Health, vol. 83, no. 11, pp. 1616-1618, 1993.

[13] C. Bellamy, The state of the world's children, United Nations Children's Fund (UNICEF), Oxford, 2005.

[14] World Health Organization, World health statistics 2010, World Health Organization, 2010.

[15] C. Way, The millennium development goals report 2015, UN, 2015. 
[16] World Health Organization, World health statistics 2016: monitoring health for the SDGs sustainable development goals, World Health Organization, 2016.

[17] UNICEF, UNICEF data: monitoring the situation of children and women, 2016.

[18] S.-R. Pasricha, A. E. Armitage, A. M. Prentice, and H. Drakesmith, "Reducing anemia in low-income countries: control of infection is essential," BMJ, vol. 362, article k3165, 2018.

[19] L. E. Bain, P. K. Awah, N. Geraldine et al., "Malnutrition in sub-Saharan Africa: burden, causes and prospects," Pan African Medical Journal, vol. 15, 2013.

[20] I. Demographic, Health survey 2016: key indicators report, CSA and ICF, Addis Ababa, Ethiopia, and Rockville, Maryland, USA, 2016.

[21] G. Abashula, N. Jibat, and T. Ayele, "The situation of orphans and vulnerable children in selected woredas and towns in Jimma Zone," International Journal of Sociology and Anthropology, vol. 6, no. 9, pp. 246-256, 2014.

[22] C. S. Agency, Ethiopia mini demographic and health survey 2014., Central Statistical Agency Addis Ababa, Ethiopia, 2014.

[23] H. Yisak, T. Gobena, and F. Mesfin, "Prevalence and risk factors for under nutrition among children under five at Haramaya district, eastern Ethiopia," BMC Pediatrics, vol. 15, no. 1, p. 212, 2015.

[24] M. Asfaw, M. Wondaferash, M. Taha, and L. Dube, "Prevalence of undernutrition and associated factors among children aged between six to fifty nine months in Bule Hora district, South Ethiopia," BMC Public Health, vol. 15, no. 1, p. 41, 2015.

[25] Y. Fekadu, A. Mesfin, D. Haile, and B. J. Stoecker, "Factors associated with nutritional status of infants and young children in Somali Region, Ethiopia: a cross- sectional study," BMC Public Health, vol. 15, no. 1, p. 846, 2015. 